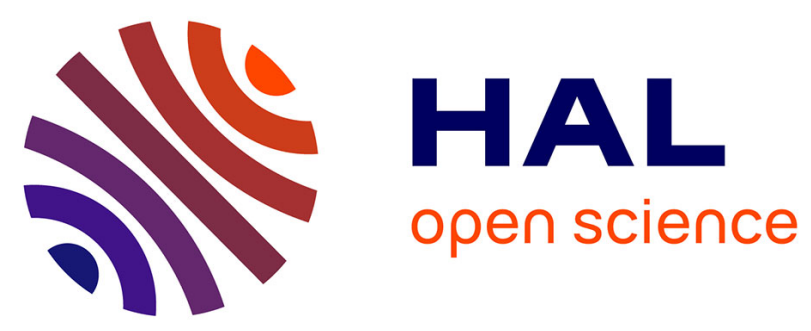

\title{
Correlative Microscopy Insight on Electrodeposited Ultrathin Graphite Oxide Films
}

\author{
Nathaly Ortiz Peña, Dris Ihiawakrim, Vincent Ball, Stefan Stanescu, Mircea \\ Rastei, Clément Sanchez, David Portehault, Ovidiu Ersen
}

\section{- To cite this version:}

Nathaly Ortiz Peña, Dris Ihiawakrim, Vincent Ball, Stefan Stanescu, Mircea Rastei, et al.. Correlative Microscopy Insight on Electrodeposited Ultrathin Graphite Oxide Films. Journal of Physical Chemistry Letters, 2020, 11 (21), pp.9117-9122. 10.1021/acs.jpclett.0c02482 hal-02998097

\section{HAL Id: hal-02998097 \\ https://hal.sorbonne-universite.fr/hal-02998097}

Submitted on 10 Nov 2020

HAL is a multi-disciplinary open access archive for the deposit and dissemination of scientific research documents, whether they are published or not. The documents may come from teaching and research institutions in France or abroad, or from public or private research centers.
L'archive ouverte pluridisciplinaire HAL, est destinée au dépôt et à la diffusion de documents scientifiques de niveau recherche, publiés ou non, émanant des établissements d'enseignement et de recherche français ou étrangers, des laboratoires publics ou privés. 


\title{
Correlative Microscopy Insight on Electrodeposited Ultrathin Graphite Oxide Films
}

\author{
Nathaly Ortiz Peña ${ }^{1 *}$, Dris Ihiawakrim ${ }^{l}$, Vincent Ball ${ }^{2,3}$, Stefan Stanescu ${ }^{4}$, Mircea Rastei ${ }^{l}$, \\ Clément Sanchez ${ }^{5,6}$, David Portehault ${ }^{5}$ Ovidiu Ersen ${ }^{1 *}$
}

${ }^{1}$ Institut de Physique et Chimie des Matériaux de Strasbourg (IPCMS), UMR 7504 CNRS Université de Strasbourg, 23 rue du Loess, BP 43, Strasbourg Cedex 2, France

${ }^{2}$ Université de Strasbourg, Faculté de Chirurgie Dentaire, 8 rue Sainte Elisabeth, 67000 Strasbourg, France

${ }^{3}$ Institut National de la Santé et de la Recherche Médicale, Unité mixte de Recherche 1121, 11 rue Humann, 67085 Strasbourg Cedex, France

${ }^{4}$ Synchrotron SOLEIL, L'Orme des Merisiers, Saint-Aubin, BP 48, Gif-sur-Yvette 91192, France

${ }^{5}$ Sorbonne Université, CNRS, Collège de France, Laboratoire Chimie de la Matière Condensée de Paris, 4 Place de Jussieu, 75005 Paris, France

${ }^{6}$ University of Strasbourg Institute for Advanced Studies (USIAS), 5 allée du Général Rouvillois, 67083 Strasbourg, France

*Email :nathaly.ortiz@ipcms.unistra.fr

*Email :ovidiu.ersen@ipcms.unistra.fr 
ABSTRACT. Here we present a correlative microscopic analysis of electrodeposited films from catechol solutions in aqueous electrolytes. The films were prepared in a miniaturized electrochemical cell and were analyzed by identical location transmission electron microscopy, scanning transmission X-ray microscopy and atomic force microscopy. Thanks to this combined approach, we have shown that the electrodeposited films are constituted of ultrathin graphite oxide nanosheets. Detailed information about the electronic structure of the films was obtained by X-ray Absorption Near Edge Structure spectroscopy. These results show the large potential of soft electrochemical conditions for the bottom-up production of ultrathin graphite oxide nanosheet films via a one-pot green chemistry approach from simple organic building blocks.

\section{TOC GRAPHICS}

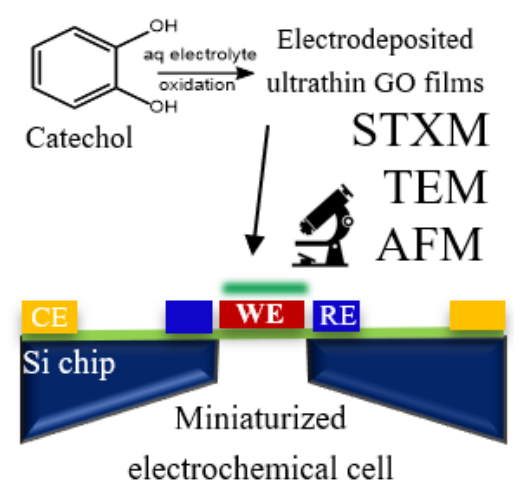

KEYWORDS. Ultrathin graphite oxide, identical location transmission electron microscopy, scanning transmission X-ray microscopy, correlative microscopy, atomic force microscopy, electrodeposition, pyrocatechol. 
Carbon-based nanostructured materials, such as graphene, nanotubes and fullerenes have attracted a wide attention of the scientific community thanks to their unique electrochemical, chemical and physical properties. ${ }^{1-5}$ Furthermore, carbon-based coatings are particularly interesting given the spectacular physical and chemical properties of such materials. Notably, graphene oxides (GrO)based coatings are largely studied for their high electrical conductivity, extraordinary mechanical strength and high young modulus. ${ }^{6}$ GrO-like coatings find several applications in material reinforcement, ${ }^{7}$ functionalizable platforms,${ }^{8}$ and tunable electronic surfaces ${ }^{9}$, catalysis ${ }^{10}$ among others. Moreover, the intrinsic presence of oxygenated groups accounts for multiple opportunities as anchoring centers, chelating agents or even as modulators of the electronic properties. This is a quasi $2 \mathrm{D}$ platform suitable to be functionalized, either covalently or non-covalently, ${ }^{11}$ with different functional groups. ${ }^{5}$

One of the most significant challenges for an extended implementation of GrO-like coatings is their production at large scale in a reproducible and simple way. ${ }^{12}$ Indeed, the refinement of electrochemical responses and selectivity of the devices based on carbon nanostructures is greatly affected by their synthesis route and their subsequent purification and functionalization. Hence, overcoming the challenges raised by large-scale and reproducible synthesis would allow the production of more compact, programmable and inexpensive devices. GrO is typically synthesized by exfoliation of graphite through an oxidation step in the so-called Hummer's method. ${ }^{13}$ This method usually employs harsh reagents and suffers from a poor control over the functionalization and thickness of the sheets with various oxygenated species. Other popular synthesis methods to obtain GrO sheets or few layers GrO consist in ultrasonic, electrochemical and chemical exfoliations ${ }^{14-16}$ from graphite. ${ }^{17}$ Although these methods are extensively used, they present 
multiple limitations including low reproducibility, low yield, and poor control in the oxidation degree $^{6,12}$

Therefore, the development of simple, repeatable and scalable production methods of thin GrO films with uniform thickness is of great interest. In this regard, the bottom-up production of nanoplatelets and nanoribbons of graphene oxide from simple organic molecules has gained interest given the control it offers over the surfaces formed. ${ }^{18}$ However, the fusion of atom-precise organic fragments to produce 2D graphene-based surfaces requires multiple synthesis steps and organic solvents not friendly with the environment. ${ }^{19}$ Thus, electrochemical deposition of organic films from aqueous electrolytes could be the key to the sustainable and simple one pot production of graphene oxide coatings. In this regard, a previous work ${ }^{20}$ has shown the electrodeposition of electroactive films from pyrocatechol aqueous solutions and this could be the key to a controlled production of GrO-based coatings. 1,2-dihydroxybenzene, also known as pyrocathecol, is a diol derived from the metabolism of multiple natural products. A redox equilibrium occurs between the reduced form, the catechol, and the oxidized form, the quinone. Subsequently, the carbons in the opposite side of the ring can be attacked nucleophilically and polymerize (Figure 1). 

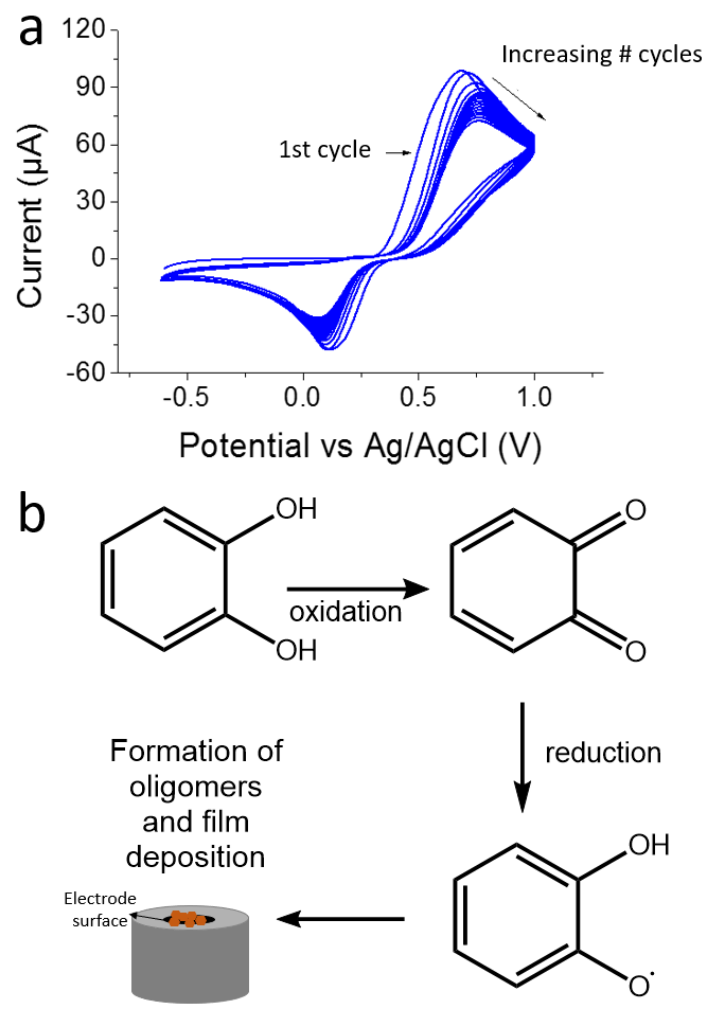

Figure 1. a) 20 cyclic voltammetry (CV) cycles of pyrocatechol at $1 \mathrm{mg} \mathrm{mL}^{-1}$ in sodium acetate $(\mathrm{pH}=5.0)$ at a potential sweep rate of $20 \mathrm{mV} \cdot \mathrm{s}^{-1}$. The current density decreases upon cycling. b) Schematic representation of electrochemical pyrocatechol film formation upon potential cycling.

Herein, we inquire in detail the structural nature of such electroposited films. We use different microscopy techniques to assess the formation of thin graphite oxide films by electrochemical reaction of pyrocatechol in aqueous solution. We employ a miniaturized electrochemical cell that allows tracking the evolution of the electrode material at different stages of the deposition by using transmission electron microscopy (TEM) and selected area electron diffraction (SAED). We then analyze the samples fabricated in the miniaturized cell by scanning transmission X-ray microscopy (STXM) and atomic force microscopy (AFM) allowing a clearer understanding of the growth process and a direct assessment of the thickness and the distribution of the oxygenated species throughout the sheets. 
An extensive analysis of the effect of the $\mathrm{pH}$ and of the nature of the organic precursor in the deposition of the film was published previously. ${ }^{20}$ Here we select the deposition conditions from pyrocatechol at $\mathrm{pH} 5$ in a potential range from -0.6 to $1 \mathrm{~V}$ vs $\mathrm{Ag} / \mathrm{AgCl}$ (Figure 1). The main electrochemical features of the resulting films were characterized in the previous study. ${ }^{20}$ Such films become impermeable to hexacyanoferrate anions and their electrochemical capacity saturates after 10 cyclic voltammetry $(\mathrm{CV})$ cycles. Furthermore, electrochemical impedance spectroscopy showed that the impedance of the film and its capacitive behavior increased with the number of $\mathrm{CV}$ cycles. A first approach to unveil the structure of the formed films was the analysis of samples recovered from the surface of the amorphous carbon electrode used in a standard three-electrodes cell. Information about the electrodeposition in the three-electrode cell can be found in the supplementary information.

To characterize the films directly formed at the surface of the amorphous carbon electrode, the electrode surface was carefully scratched after cyclic voltammetry. Since the sample is recovered from the electrode after the reaction is over we have named it ex situ post-mortem. The recovered material was deposited over a TEM copper grid. Few $\mu \mathrm{m}$ sheets, as the one shown in Figure 2a, were found all over the grid. Noticeably, throughout the sheets the electron contrast varied significantly in different regions. Assuming that the thickness of the sheets does not change considerably in the analyzed areas, later verified by AFM (Figure S2), regions with a darker contrast would correspond to organized, more crystalline order, while lighter contrast regions would arise from higher disorder degree probably related with a higher number of oxygenated functions in those regions or polymeric-like areas. High-resolution TEM (HR-TEM) images of some sheets (Figure 2b) with wide crystalline regions allowed to identify structural parameters through Fast Fourier Transform (FFT) corresponding to graphite derivatives with characteristic 
distances $(0.34 \mathrm{~nm})$ corresponding to 002 plane. On the other hand, the continuous diminution in the current density upon cycling (Figure 1a) indicates a decrease of electron transport representative of the formation of a less conductive film such as graphite oxide (GrO) rather than pristine thin graphite. Such hypothesis was corroborated by EDX yielding an elemental mapping of the sheets to display a primary composition of carbon and oxygen (Figure 2c,d). This observation would explain the above-mentioned impermeabilization of the surface towards hexacyanoferrate anions since the presence of multiple negatively charged oxygenated groups would prevent interaction of the surface with the negatively charged redox probe and then impede its detection. $^{21}$
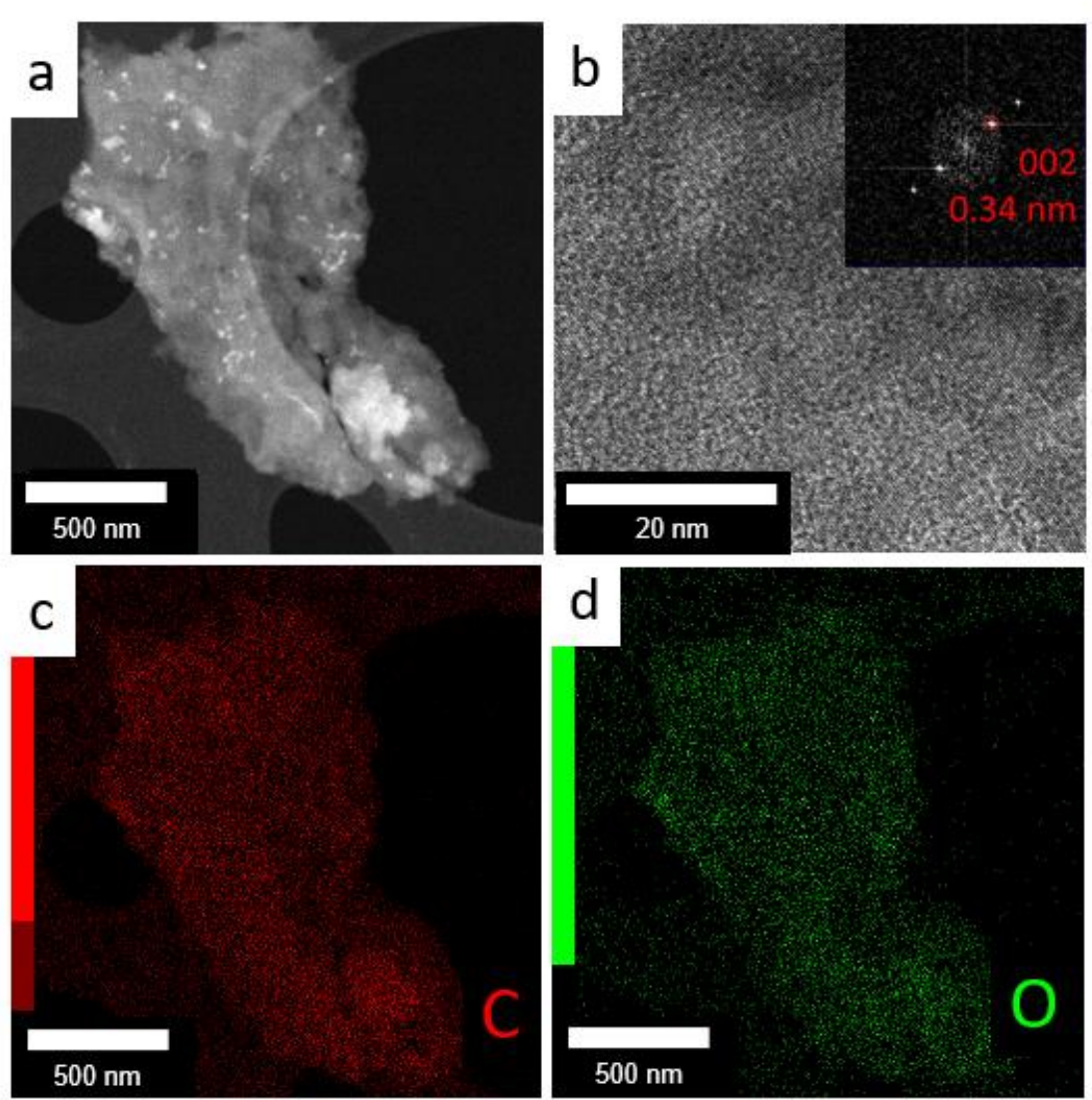
Figure 2. a) Dark-field TEM image of the material recovered from the surface of the amorphous carbon working electrode after $50 \mathrm{CV}$ cycles in a $1 \mathrm{mg} \cdot \mathrm{mL}^{-1}$ pyrocatechol buffered electrolyte sweeping the potential at $20 \mathrm{mV} \cdot \mathrm{s}^{-1}$ between -0.6 and $1.0 \mathrm{~V}$ versus $\mathrm{Ag} / \mathrm{AgCl}$. b) HR-TEM image of a sheet in the same sample. The inset corresponds to the FFT of the image. c) and d) corresponds to the elemental distribution of carbon and oxygen obtained by EDX within the sheet shown in (a), respectively.

To further inquire the formation of the films, we used a miniaturized electrochemical cell dedicated to in situ electrochemical TEM. The miniaturized cell is composed of a silicon nitride substrate - transparent to both electron and optical beams- which includes a glassy carbon working electrode (Figure S1). This geometry allows the analysis of the film directly on the substrate without the need of scratching or any additional treatment, therefore preserving at maximum the "as prepared" features. In Figure 3, one can note that the film forms not only over the electrode but also in its vicinities. Furthermore, the sheets can reach a length of few tens of $\mu \mathrm{m}$ with ripples and folds all over. Thus, the gradual decrease in the current upon cycling can be related to the degree of electrodeposition that can be reached. According to the observation in the miniaturized cell, the film tends to spread away, rather than to stack, even forming in regions out of the working electrode. AFM measurements (Figure S2) provide information on the thickness of the sheets. The thickness was found to vary between 10 to $15 \mathrm{~nm}$ throughout the films, therefore confirming a minimal variation in thickness independently from the distance of the electrode after $25 \mathrm{CV}$ cycles. Films with a regular thickness displaying lateral extensions exceeding $10^{4} \mu \mathrm{m}^{2}$ can easily be found. The surface roughness values for such regions is typically of the order of $2 \mathrm{~nm}$, which confers the films a rather homogenous morphology comparable with that of spin-coated graphene oxide films. ${ }^{22}$ These surface characteristics depend on the exact location and on the distance with respect 
to the electrode. In the immediate proximity of the electrode the growth is in general slightly thicker with rms roughness values remaining nevertheless of the order of few nanometers.

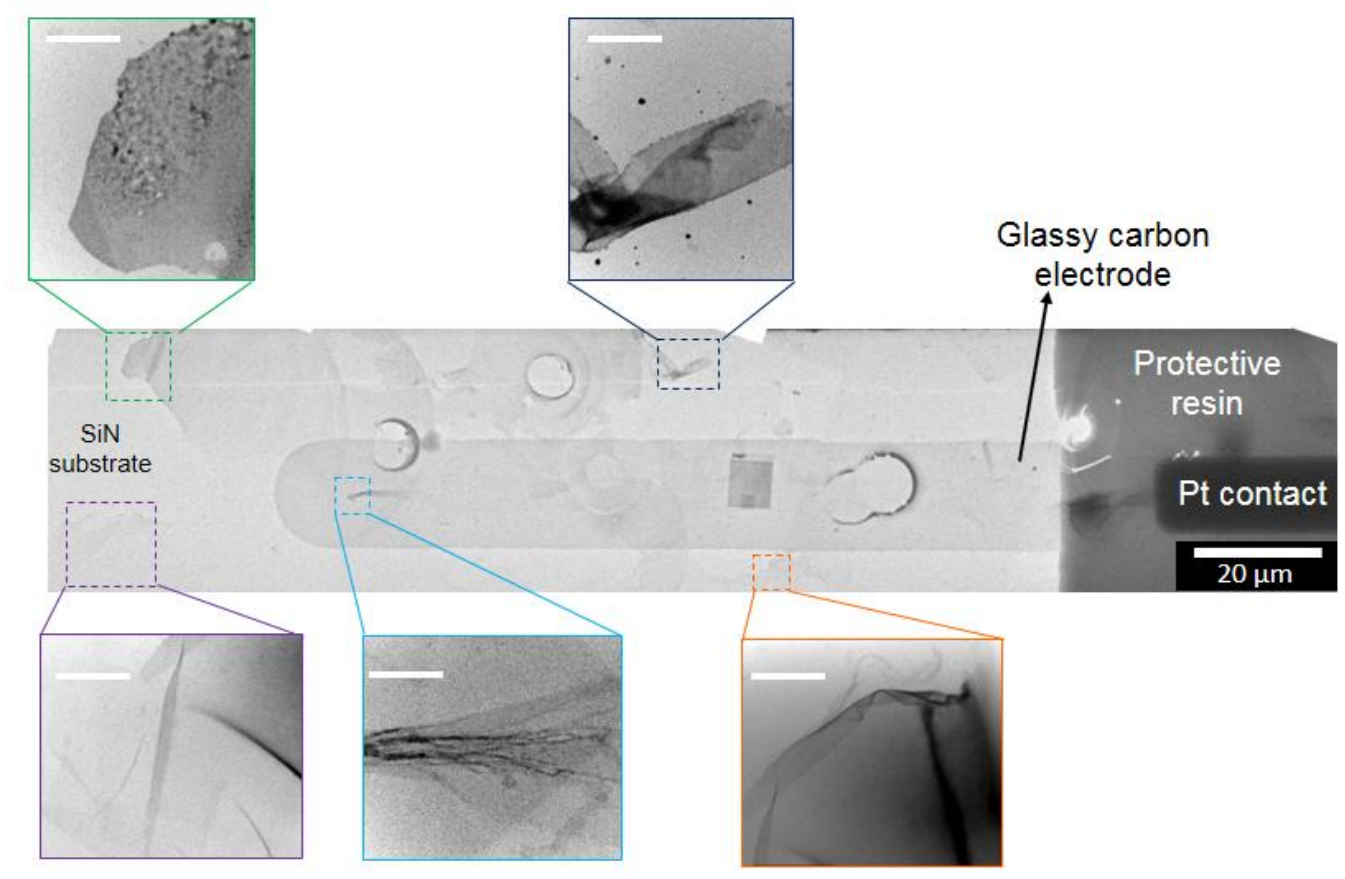

Figure 3. Global image of the miniaturized electrochemical TEM cell and of the grown layer after $25 \mathrm{CV}$ cycles. Scale bar of the insets corresponds to $2 \mu \mathrm{m}$.

Additional insights on the formation process of the GrO films was obtained thanks to the punctual tracking at different moments of the electrodeposition. By using the miniaturized cell, we followed the evolution in a specific region of interest after 2, 4 and 8 voltammetric cycles. We started by introducing the pyrocatechol solution through the microfluidic system into a pristine chip. Then, we launched the cyclic voltammetry experiment. In Figure 4, the diffraction patterns of a GrO fragment located close to the working electrode (Figure S3) are traced after having perfomed 2, 4 and 8 voltammetric cycles. From the very first 2 cycles a very intense diffraction spot with lattice spacing of $0.24 \mathrm{~nm}$ characteristic of the graphitic structure is observed. ${ }^{19,23}$ Nevertheless, this 
pattern presents also less intense diffraction rings, circled in Figure 4a, evidencing the polycrystalline character of the rest of the deposit. After 4 cycles, the rings become almost imperceptible although different spots of various intensities in the background are still distinguishable. Very close spots might arise probably from pilled-up graphene-like platelets. Finally, after 8 cycles much less diffraction spots can be detected in the background, indicating a tendency towards a higher single crystal character of the deposit.

The polycrystalline nature of the deposit after 2 cycles that tends to disappear upon cycling indicates a gradual ordering induced by the electrochemical reaction. Moreover, this suggests the progressive assembly of small crystalline blocks that can be observed in supplementary Figure $2 \mathrm{c}$. This observation would be in agreement with the formation of triphenylene-like fragments, which are known products from the oxidation of catechol. ${ }^{24}$ Here we provide with identical location TEM the evidence that such small oligomers tends to self-organize and finally form thin GrO deposits.
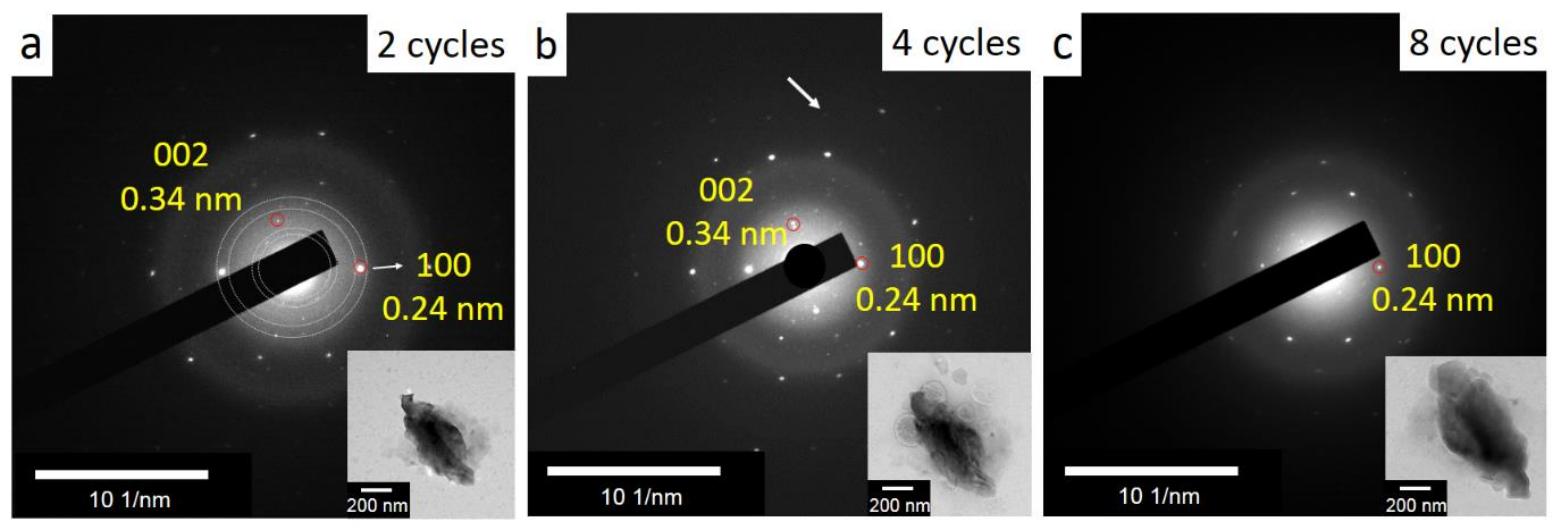

Figure 4. Electron diffraction patterns of the same area after a) 2, b) 4 and c) 8 CV cycles in the miniaturized electrochemical cell in a $1 \mathrm{mg} \cdot \mathrm{mL}^{-1}$ pyrocatechol buffered electrolyte sweeping the potential at $20 \mathrm{mV} \cdot \mathrm{s}^{-1}$. 
Valuable information about the electronic structure of the films and their chemical homogeneity was provided by synchrotron radiation-based scanning transmission X-ray microscopy (STXM). With STXM, a focused X-ray beam yields a correlated image with highly resolved spectral information taking profit from the strong XANES (X-ray Absorption Near Edge Structure) chemical and orbital selectivity. It is important to stress that the sample analyzed is the same one prepared in the miniaturized electrochemistry cell and that was used above for post-in situ electrochemical TEM and AFM. Figure 5a shows the raw STXM image in transmitted intensity units recorded at $285 \mathrm{eV}$, associated with the transition from the $\mathrm{C} 1 \mathrm{~s}$ core level to $\pi^{*}$ level. We clearly distinguish the same features as the ones in the corresponding TEM image (Figure 3). As in the TEM image, we observe a contrast difference along the two sides of the glassy carbon electrode, noted here as R1 (green) and R2 (red). The corresponding XANES at the C K edge are shown in Figure 5c. The experimental C K-edge XANES spectra are compared to the calculated elemental continuum in Figure S4c, using the relationship of the $\mu(E)$ as a function of the tabulated $f_{2}$ imaginary part of the atomic scattering factor ${ }^{25}$ and the atomic number density. We can evaluate in this way the $\mathrm{C}: \mathrm{O}$ ratio which is a direct indicator of the degree of the GrO oxidation. ${ }^{26}$ The $\mathrm{C}: \mathrm{O}$ ratio of the deposits varies between 1 and 1.75 , which is significantly lower comparatively with the theoretical value of the precursor pyrocatechol, namely 3 . This is an indication of the partial graphitization of the deposit. Such graphitization is particularly interesting given that the films are obtained at room temperature with mild electrochemical conditions in an aqueous solution. It is important to mention that the absolute values for the $\mathrm{C}: \mathrm{O}$ ratio extracted in this manner are subjected to errors due to the uncertainties in the $f_{2}$ values and a proper quantification could be obtained only using the approach proposed by Le Guillou et al. ${ }^{27}$ However, the differences of the C:O ratio from one region to another are relevant to assess the homogeneity of the oxidation level 
through the sheet. It appears thus clearly that the region $\mathrm{R} 2$ corresponds to a $\mathrm{GrO}$ more oxidized than in the $\mathrm{R} 1$ region. The highest $\mathrm{C}: \mathrm{O}$ ratio (Figure S4c, blue curve) was obtained on a small particle found inside the R2 region. It corresponds probably to an isolated reduced-GrO region, considering the absence of the spectral signature arising from different functional groups as identified in Figure 5c. Several similar "particles" are spread over the two regions and seem homogeneously distributed. Similar spreading of small "particles" was observed by TEM (Figure S3b).
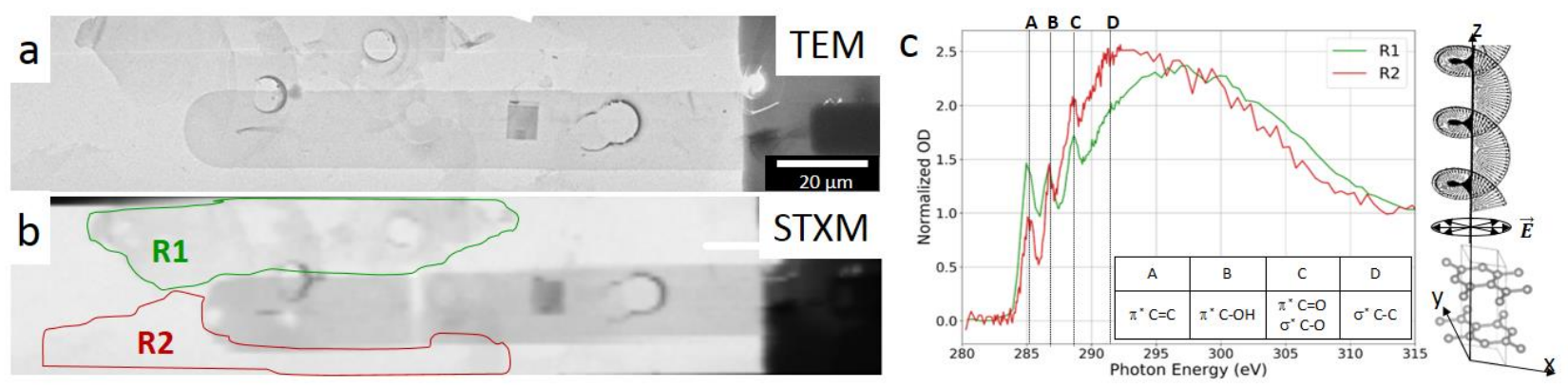

Figure 5. a) TEM image of the electrodeposited film in the miniaturized electrochemical cell. b) STXM image in transmission recorded at $285 \mathrm{eV}$ of the same region. c) Normalized C K-edge XANES spectra associated to the red and green regions. The different functional groups are identified and listed in the inset table. A strong contrast given by a net difference of the $\sigma^{*} / \pi^{*}$ ratio is evidenced. Right: geometry of the measurement showing the circular polarized light with respect to the graphene layers. Assuming normal incidence, the signal from the $\sigma$ bonds lying in the sample plane are maximized (while $\pi$ minimized) and the azimuthal anisotropy is averaged out by the isotropic light electric field vector orientation.

Due to the strong anisotropic graphene structure, we cannot exclude that part of the observed contrast in the image recorded at the $\pi^{*}$ resonance originates from the orientation contrast between the $\pi$ and $\sigma$ bonds probed using the circular polarized light. ${ }^{28,29}$ Indeed, the circular 
polarization averages all the orientations of the in-plane lying bonds and highlight a strong contrast with the out-of-plane ones. In a typical geometry depicted in Figure 5c, with the GrO layer lying perfectly in the sample plane, we would expect a complete extinction of the $\pi^{*}$ resonance. ${ }^{28}$ The $\mathrm{C}$ K-edge absorption spectra in the Figure $5 \mathrm{c}$ exhibit a visible difference between the two regions of the $\mathrm{A}$ and $\mathrm{D}$ features corresponding to the $\pi^{*}$ and $\sigma^{*}$ resonances. For the sake of comparison, the spectra were normalized at the pre-edge and post-edge spectral region in order to remove the differences due to a different $\mathrm{C}: \mathrm{O}$ ratio, as discussed above. Additional functional groups were identified according to peaks in the C K edge XANES (B and C in Figure 5), namely C-OH and $\mathrm{C}=\mathrm{O}(\mathrm{C}-\mathrm{O})$. It is clear that both, oxidation level and $\mathrm{GrO}$ orientation, contribute to the measured $\mathrm{C} \mathrm{K}$ edge absorption spectra. A possible assumption explaining the partial orientation contrast in the region R1 compared to $\mathrm{R} 2$, i.e. the $\mathrm{GrO}$ film not lying strictly in-plane, is that folded/curled/rippled sheets are largely predominant here. For instance, we focus on a small region identified by the three techniques TEM (see Figure 3, top ROI), STXM (Figure S5) and AFM (Figure S6). The STXM image in Figure S5a was obtained by averaging all images from an energy stack recorded across the $\mathrm{C} \mathrm{K}$ edge, after drift correction. We can associate it with a clock-wise rolled (from left to the right) $\mathrm{GrO}$ sheet, and 1,2 and 3 the number of revolutions. Cluster analysis (CA) was performed using the MANTIS software ${ }^{30}$ in order to separate spatial regions with spectral similarities. Figure S5b shows the CA result and Figure S5d the associated extracted XANES spectra. In the inset of Figure S5d we report the $\sigma^{*} / \pi^{*}$ ratio, representative of the orientation selectivity in this case. We remark the orientation gradient from the center to the borders of the roll, as expected, with increased $\sigma^{*} / \pi^{*}$ ratio values in the center. Nevertheless, the effect is quite limited, suggesting that the GrO sheets are highly defective. The rolling-up of the film was also observed by AFM (Figure S6) were the same region showed thicknesses going from 
around 10 to $30 \mathrm{~nm}$. The maximum height of $\sim 28 \mathrm{~nm}$ was found at the border of the roll (Figure S6e) were the curvature is added to the folded film thickness. In summary, STXM bring into light that $\mathrm{GrO}$ sheets are formed, interestingly with two distinguishable oxidation levels along the two sides of the electrode. The polarization dependent orientation contrast indicates that the $\mathrm{GrO}$ sheets are well defined, but with a high density of defects, related most probably to the high oxygen content. Furthermore, slight variations of the thickness (as observed Figure S6c and d along arrows 2 and 3, respectively) could be related with a changes in the density of defects mentioned above.

In conclusion, we have unveiled the structural nature of the electrochemically produced thin graphite oxide films by a correlated microscopy approach using TEM, STXM and AFM. We present the evidence of the bottom-up production of ultrathin graphite oxide films by electrodeposition in aqueous electrolytes from a simple organic molecule as catechol. Films produced in a miniaturized electrochemical cell were analyzed by using the multiselective approach based on the three techniques that allows a complementary understanding of the electrodeposited material. Furthermore, identical location TEM permitted to monitor the gradual evolution of the nanosheets observed within the films over the potential cycling. Additionally, STXM analysis brought light on the electronic structure of the films showing different degrees of oxidation depending of the region of the observation window. Finally, AFM measurements provided the morphological features of the deposit, by showing that the thickness of the films remained almost constant throughout the films, finding which provide direct evidence of the suitability of the method for the production of uniform micrometric ultrathin GrO films. Overall, the high benefit of correlating different microscopy and spectroscopy techniques to elucidate various aspects of nanostructured materials including morphology, topology, chemical composition and electronic structure, is clearly highlighted. 


\section{ACKNOWLEDGMENTS}

This work was supported by the French national agency for research (ANR) under the project InSiChem ANR-16-CE05-0011 and by the USIAS chair of Prof. Clément Sanchez.

SUPPORTING INFORMATION AVAILABLE: Detailed information about electrodeposition conditions in situ and ex situ. Additional TEM, STXM and AFM images and analysis conditions.

\section{REFERENCES}

(1) Ciesielski, A.; Samorì, P. Supramolecular Approaches to Graphene: From Self-Assembly to Molecule-Assisted Liquid-Phase Exfoliation. Adv. Mater. 2016, 28 (29), 6030-6051. https://doi.org/10.1002/adma.201505371.

(2) Allen, M. J.; Tung, V. C.; Kaner, R. B. Honeycomb Carbon: A Review of Graphene. Chem. Rev. 2010, 110 (1), 132-145. https://doi.org/10.1021/cr900070d.

(3) Ren, S.; Rong, P.; Yu, Q. Preparations, Properties and Applications of Graphene in Functional Devices: A Concise Review. Ceram. Int. 2018, 44 (11), 11940-11955. https://doi.org/10.1016/j.ceramint.2018.04.089.

(4) Zhong, Y.; Zhen, Z.; Zhu, H. Graphene: Fundamental Research and Potential Applications. FlatChem 2017, 4, 20-32. https://doi.org/10.1016/j.flatc.2017.06.008.

(5) Geim, A. K. Graphene: Status and Prospects. Science (80-. ). 2009, 324 (5934), 1530-1534.

(6) Zhu, Y.; Murali, S.; Cai, W.; Li, X.; Suk, J. W.; Potts, J. R.; Ruoff, R. S. Graphene and Graphene Oxide: Synthesis, Properties, and Applications. Adv. Mater. 2010, 22 (35), 39063924. https://doi.org/10.1002/adma.201001068.

(7) Ferreira, F. V.; Brito, F. S.; Franceschi, W.; Simonetti, E. A. N.; Cividanes, L. S.; Chipara, M.; Lozano, K. Functionalized Graphene Oxide as Reinforcement in Epoxy Based Nanocomposites. Surfaces and Interfaces 2018, 10 (October 2017), 100-109. 
https://doi.org/10.1016/j.surfin.2017.12.004.

(8) Bouchareb, S.; Doufnoune, R.; Riahi, F.; Cherif-Silini, H.; Belbahri, L. Non-Covalent Functionalization of Graphene Oxide Using Self-Assembly of Silver-Triphenylphosphine for Bactericidal Formulations. Mater. Chem. Phys. 2020, 243 (November 2019), 122598. https://doi.org/10.1016/j.matchemphys.2019.122598.

(9) Upadhyay, R. K.; Naicker, S.; Barman, A.; Roy, S. S.; Thundat, T.; Waghmare, P. R. Fabrication of Free-Standing Graphene Oxide Films Using a Facile Approach Toluene Swollen Paraffin Peeling and Green Reduction of These Films into Highly Conductive Reduced Graphene Oxide Films. Chem. Eng. J. 2018, 354 (March), 149-161. https://doi.org/10.1016/j.cej.2018.07.189.

(10) Sajjad, S.; Khan Leghari, S. A.; Iqbal, A. Study of Graphene Oxide Structural Features for Catalytic, Antibacterial, Gas Sensing, and Metals Decontamination Environmental Applications. ACS Appl. Mater. Interfaces 2017, 9 (50), 43393-43414. https://doi.org/10.1021/acsami.7b08232.

(11) Ihiawakrim, D.; Ersen, O.; Melin, F.; Hellwig, P.; Janowska, I.; Begin, D.; Baaziz, W.; Begin-Colin, S.; Pham-Huu, C.; Baati, R. A Single-Stage Functionalization and Exfoliation Method for the Production of Graphene in Water: Stepwise Construction of 2DNanostructured Composites with Iron Oxide Nanoparticles. Nanoscale 2013, 5 (19), 90739080. https://doi.org/10.1039/c3nr02684a.

(12) Nishina, Y.; Eigler, S. Chemical and Electrochemical Synthesis of Graphene Oxide - a Generalized View. Nanoscale 2020, $12 \quad$ (24), 12731-12740. https://doi.org/10.1039/D0NR02164D.

(13) William S. Hummers, J.; Offeman, R. E. Preparation of Graphitic Oxide. J. Am. Chem. Soc 
1958, 80 (1937), 1339. https://doi.org/10.1021/ja01539a017.

(14) Ogino, I.; Yokoyama, Y.; Iwamura, S.; Mukai, S. R. Exfoliation of Graphite Oxide in Water without Sonication: Bridging Length Scales from Nanosheets to Macroscopic Materials. Chem. Mater. 2014, 26 (10), 3334-3339. https://doi.org/10.1021/cm501305c.

(15) Brisebois, P. P.; Siaj, M. Harvesting Graphene Oxide - Years 1859 to 2019: A Review of Its Structure, Synthesis, Properties and Exfoliation. J. Mater. Chem. C 2020, 8 (5), $1517-$ 1547. https://doi.org/10.1039/C9TC03251G.

(16) Liu, F.; Wang, C.; Sui, X.; Riaz, M. A.; Xu, M.; Wei, L.; Chen, Y. Synthesis of Graphene Materials by Electrochemical Exfoliation: Recent Progress and Future Potential. Carbon Energy 2019, 1 (2), 173-199. https://doi.org/10.1002/cey2.14.

(17) Wei, D.; Grande, L.; Chundi, V.; White, R.; Bower, C.; Andrew, P.; Ryhänen, T. Graphene from Electrochemical Exfoliation and Its Direct Applications in Enhanced Energy Storage Devices. Chem. Commun. 2012, 48 (9), 1239-1241. https://doi.org/10.1039/C2CC16859F.

(18) Tang, L.; Li, X.; Ji, R.; Teng, K. S.; Tai, G.; Ye, J.; Wei, C.; Lau, S. P. Bottom-up Synthesis of Large-Scale Graphene Oxide Nanosheets. J. Mater. Chem. 2012, 22 (12), 5676-5683. https://doi.org/10.1039/c2jm15944a.

(19) Jordan, R. S.; Wang, Y.; McCurdy, R. D.; Yeung, M. T.; Marsh, K. L.; Khan, S. I.; Kaner, R. B.; Rubin, Y. Synthesis of Graphene Nanoribbons via the Topochemical Polymerization and Subsequent Aromatization of a Diacetylene Precursor. Chem 2016, 1 (1), 78-90. https://doi.org/10.1016/j.chempr.2016.06.010.

(20) Ball, V. Electrodeposition of Pyrocatechol Based Films: Influence of Potential Scan Rate, Pyrocatechol Concentration and PH. Colloids Surfaces A Physicochem. Eng. Asp. 2017, 518, 109-115. https://doi.org/10.1016/j.colsurfa.2017.01.012. 
(21) Lounasvuori, M. M.; Rosillo-Lopez, M.; Salzmann, C. G.; Caruana, D. J.; Holt, K. B. Electrochemical Characterisation of Graphene Nanoflakes with Functionalised Edges. Faraday Discuss. 2014, 172 (Cv), 293-310. https://doi.org/10.1039/c4fd00034j.

(22) Becerril, H. A.; Mao, J.; Liu, Z.; Stoltenberg, R. M.; Bao, Z.; Chen, Y. Evaluation of Solution-Processed Reduced Graphene Oxide Films as Transparent Conductors. ACS Nano 2008, 2 (3), 463-470. https://doi.org/10.1021/nn700375n.

(23) Bordes, E.; Morcos, B.; Bourgogne, D.; Andanson, J.-M.; Bussière, P.-O.; Santini, C. C.; Benayad, A.; Costa Gomes, M.; Pádua, A. A. H. Dispersion and Stabilization of Exfoliated Graphene in Ionic Liquids. Front. Chem. 2019, 7 (MAR), 1-14. https://doi.org/10.3389/fchem.2019.00223.

(24) Voisin, E.; Williams, V. E. Do Catechol Derivatives Electropolymerize? Macromolecules 2008, 41 (9), 2994-2997. https://doi.org/10.1021/ma800320j.

(25) Henke, B. L.; Gullikson, E. M.; Davis, J. C. X-Ray Interactions: Photoabsorption, Scattering, Transmission, and Reflection at $\mathrm{E}=50-30,000 \mathrm{EV}, \mathrm{Z}=1-92$. Atomic Data and Nuclear Data Tables. 1993, pp 181-342. https://doi.org/10.1006/adnd.1993.1013.

(26) Chen, C. H.; Hu, S.; Shih, J. F.; Yang, C. Y.; Luo, Y. W.; Jhang, R. H.; Chiang, C. M.; Hung, Y. J. Effective Synthesis of Highly Oxidized Graphene Oxide That Enables WaferScale Nanopatterning: Preformed Acidic Oxidizing Medium Approach. Sci. Rep. 2017, 7 (1), 1-10. https://doi.org/10.1038/s41598-017-04139-0.

(27) Le Guillou, C.; Bernard, S.; De La Pena, F.; Le Brech, Y. XANES-Based Quantification of Carbon Functional Group Concentrations. Anal. Chem. 2018, 90 (14), 8379-8386. https://doi.org/10.1021/acs.analchem.8b00689.

(28) Zhou, J. G.; Wang, J.; Sun, C. L.; Maley, J. M.; Sammynaiken, R.; Sham, T. K.; Pong, W. 
F. Nano-Scale Chemical Imaging of a Single Sheet of Reduced Graphene Oxide. J. Mater. Chem. 2011, 21 (38), 14622-14630. https://doi.org/10.1039/c1jm11071c.

(29) Schultz, B. J.; Patridge, C. J.; Lee, V.; Jaye, C.; Lysaght, P. S.; Smith, C.; Barnett, J.; Fischer, D. A.; Prendergast, D.; Banerjee, S. Imaging Local Electronic Corrugations and Doped Regions in Graphene. Nat. Commun. 2011, 2 (1), 372 (1-8). https://doi.org/10.1038/ncomms1376.

(30) Lerotic, M.; Mak, R.; Wirick, S.; Meirer, F.; Jacobsen, C. MANTiS: A Program for the Analysis of X-Ray Spectromicroscopy Data. J. Synchrotron Radiat. 2014, 21 (5), 12061212. https://doi.org/10.1107/S1600577514013964.

(1) Ciesielski, A.; Samorì, P. Supramolecular Approaches to Graphene: From Self-Assembly to Molecule-Assisted Liquid-Phase Exfoliation. Adv. Mater. 2016, 28 (29), 6030-6051. https://doi.org/10.1002/adma.201505371.

(2) Allen, M. J.; Tung, V. C.; Kaner, R. B. Honeycomb Carbon: A Review of Graphene. Chem. Rev. 2010, 110 (1), 132-145. https://doi.org/10.1021/cr900070d.

(3) Ren, S.; Rong, P.; Yu, Q. Preparations, Properties and Applications of Graphene in Functional Devices: A Concise Review. Ceram. Int. 2018, 44 (11), 11940-11955. https://doi.org/10.1016/j.ceramint.2018.04.089.

(4) Zhong, Y.; Zhen, Z.; Zhu, H. Graphene: Fundamental Research and Potential Applications. FlatChem 2017, 4, 20-32. https://doi.org/10.1016/j.flatc.2017.06.008.

(5) Geim, A. K. Graphene: Status and Prospects. Science (80-. ). 2009, 324 (5934), 1530-1534.

(6) Zhu, Y.; Murali, S.; Cai, W.; Li, X.; Suk, J. W.; Potts, J. R.; Ruoff, R. S. Graphene and Graphene Oxide: Synthesis, Properties, and Applications. Adv. Mater. 2010, 22 (35), 3906- 
3924. https://doi.org/10.1002/adma.201001068.

(7) Ferreira, F. V.; Brito, F. S.; Franceschi, W.; Simonetti, E. A. N.; Cividanes, L. S.; Chipara, M.; Lozano, K. Functionalized Graphene Oxide as Reinforcement in Epoxy Based Nanocomposites. Surfaces and Interfaces 2018, 10 (October 2017), 100-109. https://doi.org/10.1016/j.surfin.2017.12.004.

(8) Bouchareb, S.; Doufnoune, R.; Riahi, F.; Cherif-Silini, H.; Belbahri, L. Non-Covalent Functionalization of Graphene Oxide Using Self-Assembly of Silver-Triphenylphosphine for Bactericidal Formulations. Mater. Chem. Phys. 2020, 243 (November 2019), 122598. https://doi.org/10.1016/j.matchemphys.2019.122598.

(9) Upadhyay, R. K.; Naicker, S.; Barman, A.; Roy, S. S.; Thundat, T.; Waghmare, P. R. Fabrication of Free-Standing Graphene Oxide Films Using a Facile Approach Toluene Swollen Paraffin Peeling and Green Reduction of These Films into Highly Conductive Reduced Graphene Oxide Films. Chem. Eng. J. 2018, 354 (March), 149-161. https://doi.org/10.1016/j.cej.2018.07.189.

(10) Sajjad, S.; Khan Leghari, S. A.; Iqbal, A. Study of Graphene Oxide Structural Features for Catalytic, Antibacterial, Gas Sensing, and Metals Decontamination Environmental Applications. ACS Appl. Mater. Interfaces 2017, 9 (50), 43393-43414. https://doi.org/10.1021/acsami.7b08232.

(11) Ihiawakrim, D.; Ersen, O.; Melin, F.; Hellwig, P.; Janowska, I.; Begin, D.; Baaziz, W.; Begin-Colin, S.; Pham-Huu, C.; Baati, R. A Single-Stage Functionalization and Exfoliation Method for the Production of Graphene in Water: Stepwise Construction of 2DNanostructured Composites with Iron Oxide Nanoparticles. Nanoscale 2013, 5 (19), 90739080. https://doi.org/10.1039/c3nr02684a. 
(12) Nishina, Y.; Eigler, S. Chemical and Electrochemical Synthesis of Graphene Oxide - a Generalized View. Nanoscale 2020, $12 \quad$ (24), 12731-12740. https://doi.org/10.1039/D0NR02164D.

(13) William S. Hummers, J.; Offeman, R. E. Preparation of Graphitic Oxide. J. Am. Chem. Soc 1958, 80 (1937), 1339. https://doi.org/10.1021/ja01539a017.

(14) Ogino, I.; Yokoyama, Y.; Iwamura, S.; Mukai, S. R. Exfoliation of Graphite Oxide in Water without Sonication: Bridging Length Scales from Nanosheets to Macroscopic Materials. Chem. Mater. 2014, 26 (10), 3334-3339. https://doi.org/10.1021/cm501305c.

(15) Brisebois, P. P.; Siaj, M. Harvesting Graphene Oxide - Years 1859 to 2019: A Review of Its Structure, Synthesis, Properties and Exfoliation. J. Mater. Chem. C 2020, 8 (5), $1517-$ 1547. https://doi.org/10.1039/C9TC03251G.

(16) Liu, F.; Wang, C.; Sui, X.; Riaz, M. A.; Xu, M.; Wei, L.; Chen, Y. Synthesis of Graphene Materials by Electrochemical Exfoliation: Recent Progress and Future Potential. Carbon Energy 2019, 1 (2), 173-199. https://doi.org/10.1002/cey2.14.

(17) Wei, D.; Grande, L.; Chundi, V.; White, R.; Bower, C.; Andrew, P.; Ryhänen, T. Graphene from Electrochemical Exfoliation and Its Direct Applications in Enhanced Energy Storage Devices. Chem. Commun. 2012, 48 (9), 1239-1241. https://doi.org/10.1039/C2CC16859F.

(18) Tang, L.; Li, X.; Ji, R.; Teng, K. S.; Tai, G.; Ye, J.; Wei, C.; Lau, S. P. Bottom-up Synthesis of Large-Scale Graphene Oxide Nanosheets. J. Mater. Chem. 2012, 22 (12), 5676-5683. https://doi.org/10.1039/c2jm15944a.

(19) Jordan, R. S.; Wang, Y.; McCurdy, R. D.; Yeung, M. T.; Marsh, K. L.; Khan, S. I.; Kaner, R. B.; Rubin, Y. Synthesis of Graphene Nanoribbons via the Topochemical Polymerization and Subsequent Aromatization of a Diacetylene Precursor. Chem 2016, 1 (1), 78-90. 
https://doi.org/10.1016/j.chempr.2016.06.010.

(20) Ball, V. Electrodeposition of Pyrocatechol Based Films: Influence of Potential Scan Rate, Pyrocatechol Concentration and PH. Colloids Surfaces A Physicochem. Eng. Asp. 2017, 518, 109-115. https://doi.org/10.1016/j.colsurfa.2017.01.012.

(21) Lounasvuori, M. M.; Rosillo-Lopez, M.; Salzmann, C. G.; Caruana, D. J.; Holt, K. B. Electrochemical Characterisation of Graphene Nanoflakes with Functionalised Edges. Faraday Discuss. 2014, 172 (Cv), 293-310. https://doi.org/10.1039/c4fd00034j.

(22) Becerril, H. A.; Mao, J.; Liu, Z.; Stoltenberg, R. M.; Bao, Z.; Chen, Y. Evaluation of Solution-Processed Reduced Graphene Oxide Films as Transparent Conductors. ACS Nano 2008, 2 (3), 463-470. https://doi.org/10.1021/nn700375n.

(23) Bordes, E.; Morcos, B.; Bourgogne, D.; Andanson, J.-M.; Bussière, P.-O.; Santini, C. C.; Benayad, A.; Costa Gomes, M.; Pádua, A. A. H. Dispersion and Stabilization of Exfoliated Graphene in Ionic Liquids. Front. Chem. 2019, 7 (MAR), 1-14. https://doi.org/10.3389/fchem.2019.00223.

(24) Voisin, E.; Williams, V. E. Do Catechol Derivatives Electropolymerize? Macromolecules 2008, 41 (9), 2994-2997. https://doi.org/10.1021/ma800320j.

(25) Henke, B. L.; Gullikson, E. M.; Davis, J. C. X-Ray Interactions: Photoabsorption, Scattering, Transmission, and Reflection at $\mathrm{E}=50-30,000 \mathrm{EV}, \mathrm{Z}=1-92$. Atomic Data and Nuclear Data Tables. 1993, pp 181-342. https://doi.org/10.1006/adnd.1993.1013.

(26) Chen, C. H.; Hu, S.; Shih, J. F.; Yang, C. Y.; Luo, Y. W.; Jhang, R. H.; Chiang, C. M.; Hung, Y. J. Effective Synthesis of Highly Oxidized Graphene Oxide That Enables WaferScale Nanopatterning: Preformed Acidic Oxidizing Medium Approach. Sci. Rep. 2017, 7 (1), 1-10. https://doi.org/10.1038/s41598-017-04139-0. 
(27) Le Guillou, C.; Bernard, S.; De La Pena, F.; Le Brech, Y. XANES-Based Quantification of Carbon Functional Group Concentrations. Anal. Chem. 2018, 90 (14), 8379-8386. https://doi.org/10.1021/acs.analchem.8b00689.

(28) Zhou, J. G.; Wang, J.; Sun, C. L.; Maley, J. M.; Sammynaiken, R.; Sham, T. K.; Pong, W. F. Nano-Scale Chemical Imaging of a Single Sheet of Reduced Graphene Oxide. J. Mater. Chem. 2011, 21 (38), 14622-14630. https://doi.org/10.1039/c1jm11071c.

(29) Schultz, B. J.; Patridge, C. J.; Lee, V.; Jaye, C.; Lysaght, P. S.; Smith, C.; Barnett, J.; Fischer, D. A.; Prendergast, D.; Banerjee, S. Imaging Local Electronic Corrugations and Doped Regions in Graphene. Nat. Commun. 2011, 2 (1), 372 (1-8). https://doi.org/10.1038/ncomms1376.

(30) Lerotic, M.; Mak, R.; Wirick, S.; Meirer, F.; Jacobsen, C. MANTiS: A Program for the Analysis of X-Ray Spectromicroscopy Data. J. Synchrotron Radiat. 2014, 21 (5), 12061212. https://doi.org/10.1107/S1600577514013964. 